\title{
Analgesic effect of preoperative intravenous administration of paracetamol on post-cesarean pain: A randomized clinical trial
}

Seyyed Hamid Pakzad Moghadam

Rafsanjan University of Medical Sciences

Masoud Pourparizi

Rafsanjan University of Medical Sciences

Reza Goujani

Rafsanjan University of Medical Sciences

Tayyebeh Mirzaei Khalilabadi

Rafsanjan University of Medical Sciences

Ali Ravari

Rafsanjan University of Medical Sciences

Shayesteh Askari

Rafsanjan University of Medical Sciences

Sakineh Mirzaei Khalilabadi ( $\nabla$ mirzaie_sk@yahoo.com)

Rafsanjan University of Medical Sciences

Research article

Keywords: Cesarean Section, Pain, Paracetamol, Pethidine

Posted Date: December 16th, 2019

DOI: https://doi.org/10.21203/rs.2.18913/v1

License: (a) (i) This work is licensed under a Creative Commons Attribution 4.0 International License. Read Full License 


\section{Abstract}

Background Pain control after every surgery, especially cesarean is highly important, and physicians are striving to discover pain control methods using the least amount of opioid and Paracetamol is a non-opioid analgesic with few complications. The present study was aimed to investigate the analgesic effect of preoperative intravenous administration of paracetamol on post-cesarean pain.

Methods This randomized double-blind clinical trial was conducted on 240 pregnant women under spinal anesthesia who were candidate for elective cesarean. The patients' weight, height, age and body mass index (BMI) were recorded, and patients were randomly divided into two equal groups $(n=120)$. In the first group, $10 \mathrm{mg} / \mathrm{kg}$ paracetamol in 100cc normal saline (paracetamol group) and in the second group 100cc normal saline (control group) administered 15 minutes before surgery intravenously. Blood pressure, pulse rate, chills and nausea were recorded during and 1 hour after surgery, and pain visual analogue scale (VAS) and need for additional analgesic were recorded 1, 2, 4, 6, 12 and 24 hours after surgery.

Results No significant difference was found between the two groups in frequency of chills and nausea $(p>0.05)$. Mean pethidine consumed was lower in paracetamol group than control group but not significantly. Systolic blood pressure of both groups during surgery and one hour after surgery did not show a significant difference, but diastolic blood pressure was significantly lower in paracetamol group 15 minutes $(p=0.046)$ and 60 minutes after surgery $(p=0.042)$ than control group. The mean scores of pain were significantly lower in paracetamol group than control group 6 hours $(0.008)$ and 24 hours $(p=0.038)$ after surgery.

Conclusions Within the limitations of the current study, preoperative intravenous administration of paracetamol significantly reduced post-cesarean pain within 24 hours.

\section{Background}

The International Association for the Study of Pain has defined pain as an unpleasant feeling and mental experience associated with potential or real tissue damage. Pain is one of the most common symptoms and signs of diseases that informs an individual of a dysfunction in a part of his body (1). Following all surgical procedures, the patients experience pain inevitably in various degrees (2).

On the other hand, cesarean is one of the most significant surgical procedures in obstetrics and gynecology (3) that is used as a strategy to save the lives of mother and child in hard deliveries (4) and is currently a frequently used surgery (3). In cesarean section, there is acute pain due to complex physiologic reaction against to histological damage, visceral dilation and uterine contractions $(5,6)$. If the post-cesarean pain is not controlled and managed well, it can have adverse effects on different body systems, such as inability to discharge secretions of respiratory system, increased blood pressure and heart rate and prolonged bed rest, thereby increasing the risk of deep vein thrombosis, delayed breastfeeding and inappropriate neonatal nutrition (7). 
To relive post-cesarean pain, opioids and nonsteroidal anti-inflammatory drugs (NSAIDs) are widely used (8). Pethidine (meperidine) is the most frequently used opioids during delivery. Pethidine bonds to the opioid receptors of central nervous system, so inhibits the ascending pain pathway and reduces the pain perception (9).

Unlike opioids, non-opioids analgesics have advantages like lack of effect on breastfeeding, absence of respiratory weakness, absence of drug abuse potential, low narcotic effects, early return of bowel function and quicker improvement $(10,11)$.

Paracetamol, is a non-opioid antipyretic and analgesic drug $(12,13)$ that acts through inhibition of production of prostaglandins. It is one of the highly consumed drugs around the world (14). The onset of its analgesic effect ranges from 5 to 10 minutes, and its maximum effect is one hour, lasting from 4-6 hours $(12,13)$.

Given the significance of post-cesarean pain control as well as the side effects of opioid analgesics, this study was conducted to determine the preoperative analgesic effect of intravenous paracetamol on postcesarean pain control.

\section{Methods}

The proposal of present study approved by the Research Council of Rafsanjan University of Medical Sciences with No. 841 on 2016-11-08 and by the ethics committee of Rafsanjan University of Medical Sciences, with code IR.RUMS.REC.1395.115 on 2016-11-08, and also approved by the Iranian Registry of Clinical Trial (IRCT) with code IRCT20150519022320N17 on 2019-01-18.

This randomized double-blind clinical trial conducted on 240 pregnant women aged 18-40 years referring to Niknafas maternity hospital in Rafsanjan, Iran for elective cesarean section. The sample size was determined based on the Jabalameli M study(15). Trial design was parallel and the allocation ratio was 1:1. The exclusion criteria consisted of patients with history of cardiovascular diseases, hypertension, diabetes, hepatic and renal failure, psychiatric disorders, specific drug-dependency, drug abuser, and those prohibited from paracetamol or pethidine consumption. Exclusion criteria confirmed through questionnaire before surgery. In addition, patients undergoing general anesthesia, receiving pethidine during surgery or having complicated surgery excluded from the study and replaced by new patients.

The study was carried out during 2017-2018. Patient medical history recorded and the study and pain severity measurement method, consumption drugs and their side effects were explained to the patients. Then, a questionnaire, including demographic information and research variables, was completed for each patient, and informed written consent was taken. The patients who agreed to take part in the study were randomly assigned to two groups of paracetamol $(n=120)$ and control $(n=120)$. We used simple randomized pairing method. Patients with general entry conditions are divided into two groups by throwing coins. When a group reaches 120 , the other referrals are assigned to another group. The operating room nurse determines the group of each patient and each patient's group records in their own record sheet, surgeon, researcher and patient will not aware about the group. 
All patients kept NPO for 8 hours, during which time the hydration therapy was prepared according to the one, two and four rules using Ringer's solution (Shahid Ghazi pharmaceutical Co, Tabriz, Iran). Paracetamol group was administered intravenous $10 \mathrm{mg} / \mathrm{kg}$ paracetamol (Exir Pharmaceutical Co, Borujerd, Iran) dissolved in $100 \mathrm{cc}$ normal saline (Shahid Ghazi, pharmaceutical Co, Tabriz, Iran) before surgery. The control group was administered $100 \mathrm{cc}$ normal saline intravenously before surgery. The patients were blind to the type of group they were assigned to, either case or control. The drug administered by an out of research nurse before surgery, and the patient immediately transferred to the operative room. All patients received $10 \mathrm{cc} / \mathrm{kg}$ Ringer's solution before spinal anesthesia and were administered intravenous $10 \mathrm{mg}$ metoclopramide (Daru Pakhsh Co, Tehran, Iran). Spinal anesthesia was performed by spinal needle no 25 (Dr. J, China) and $2.5 \mathrm{cc}$ of Marcaine $5.0 \%$ (Mylan, France), totally $12.5 \mathrm{mg}$, in a sitting position. After performing spinal anesthesia and reaching appropriate anesthetic level (T4), cesarean section was carried out. If the Mean Arterial Pressure (MAP) drop more than $20 \%$ of base level, the patients received $5 \mathrm{mg}$ Ephedrine (STEROP, Brussels, Belgium). After delivery, all patients were administered $1 \mathrm{mg}$ of midazolam (Tehran Shimi Co, Tehran Iran) intravenously. A trained anesthetic technician recorded vital signs at baseline (after placement on the bed and doing anesthesia) and then every 15 minutes until the end of surgery and 1 hour after surgery, nausea, vomiting and chills during and after surgery. All patients underwent spinal anesthesia by one anesthesiologist and cesarean by one surgeon, and the surgeon and the anesthesiologist were out of research team.

After surgery, a trained person trained Visual Analogue Scale (VAS) to the patients again. Zero showed no pain and ten indicated the worst level of pain (16). VAS was recorded 1, 2, 4, 6, 12 and 24 hours after surgery. Pain score was determined by VAS scoring ruler (Fig. 1). If VAS was $>5$, pethidine $(25 \mathrm{mg})$ was administered intravenously in an ascending manner. Also, the mean dose of pethidine intake was recorded in the first 24 hours. The obtained data were analyzed by SPSS software using parametric and nonparametric statistical tests (t-test, chi-square, Mann-Whitny). Significance level was determind $P<0.05$ for all analyzes.

\section{Results}

All study participants (both the intervention and the control group) received their own therapeutic interventions and remained in the study to the end. The number of participants excluded after the randomization was zero. Therefore, data of all participants was used in all analyzes.

The results of independent t-test showed no significant difference between the two groups in weight, height, age and BMI (Table 1). 
Table 1

Comparison of age, weight, height and BMI between paracetamol and control groups

\begin{tabular}{|lllll|}
\hline Variable & Paracetamol & Control & Total & P-Value \\
\cline { 2 - 5 } & Mean \pm SD & Mean \pm SD & Mean \pm SD & \\
\hline Age (year) & $31.55 \pm 7.13$ & $30.64 \pm 6.72$ & $31.10 \pm 6.96$ & 0.310 \\
\hline Weight $(\mathrm{kg})$ & $80.06 \pm 12.61$ & $79.57 \pm 14.90$ & $79.82 \pm 13.77$ & 0.787 \\
\hline Height $(\mathrm{m})$ & $158.73 \pm 9.83$ & $160.43 \pm 5.87$ & $159.60 \pm 8.08$ & 0.118 \\
BMl & $31.58 \pm 5.06$ & $30.81 \pm 5.74$ & $31.19 \pm 5.42$ & 0.290 \\
\hline
\end{tabular}

The findings of chi-square test showed no significance difference between paracetamol and control groups in frequency of post-surgery chills and nausea (Table 2).

Table 2

Frequency of post-cesarean chills and nausea in pregnant women in paracetamol and control groups

\begin{tabular}{|c|c|c|c|c|c|c|c|c|}
\hline \multirow[t]{2}{*}{ Variable } & & \multicolumn{2}{|c|}{ Paracetamol } & \multicolumn{2}{|l|}{ Control } & \multicolumn{2}{|l|}{ Total } & \multirow{2}{*}{$\begin{array}{l}\text { P- } \\
\text { Value }\end{array}$} \\
\hline & Index & Number & Percentage & Number & Percentage & Number & Percentage & \\
\hline \multirow[t]{2}{*}{ Chills } & Yes & 15 & 12.6 & 18 & 15.7 & 33 & 14.1 & \multirow[t]{2}{*}{0.315} \\
\hline & No & 104 & 87.4 & 97 & 84.3 & 201 & 85.9 & \\
\hline \multirow[t]{2}{*}{ Nausea } & Yes & 24 & 20 & 18 & 15 & 42 & 17.5 & \multirow[t]{2}{*}{0.198} \\
\hline & No & 96 & 80 & 102 & 85 & 198 & 82.5 & \\
\hline
\end{tabular}

The results of Mann-Whitney test revealed that the mean scores of pain at 6 and 24 hours after surgery were significantly lower in paracetamol group than control group. There was no significant difference between the two groups in the mean scores of pain at the other times. Figure 1 shows the changes of mean scores of pain in both study groups over time (Table 3).

Table 3

Mean and standard deviation of pain scores at different hours after surgery in paracetamol and control groups

\begin{tabular}{|lllllll|}
\hline Group & $\mathbf{1}$ hour & $\mathbf{2}$ hours & 4 hours & $\mathbf{6}$ hours & 12 hours & 24 hours \\
\hline Paracetamol & $0.82 \pm 1.83$ & $3.38 \pm 2.43$ & $4.58 \pm 2.58$ & $4.01 \pm 2.22$ & $2.94 \pm 1.78$ & $2.26 \pm 1.85$ \\
\hline Control & $0.72 \pm 1.48$ & $3.87 \pm 2.45$ & $5.13 \pm 2.36$ & $4.83 \pm 2.35$ & $3.37 \pm 1.92$ & $2.67 \pm 1.80$ \\
\hline P-Value & 0.573 & 0.108 & 0.082 & 0.008 & 0.072 & 0.038 \\
\hline
\end{tabular}


Pethidine consumption 24 hours after surgery was lower in paracetamol group than control group although Mann-Whitney test showed no significant difference between the groups (Table 4).

Table 4

Mean consumption of pethidine 24 hours

after surgery in paracetamol and control

groups

\begin{tabular}{|ll|}
\hline Group & Pethidine $(\mathrm{mg})$ Mean \pm SD \\
\hline Paracetamol & $34.78 \pm 12.47$ \\
\hline Control & $40.53 \pm 58.12$ \\
\hline P-Value & 0.245 \\
\hline
\end{tabular}

Mann-Whitney test indicated no significant difference between the two groups in mean pulse rate at all study times (Table 5)

Table 5

Mean and standard deviation of pulse rate at different hours after surgery in paracetamol and control groups

\begin{tabular}{|lllll|}
\hline Group & 15 minutes & 30 minutes & 45 minutes & 60 minutes \\
\hline Paracetamol & $91.21 \pm 19.87$ & $96.62 \pm 17.75$ & $93.78 \pm 14.00$ & $95.40 \pm 12.66$ \\
\hline Control & $94.31 \pm 19.46$ & $94.75 \pm 17.47$ & $96.81 \pm 14.83$ & $97.84 \pm 16.63$ \\
\hline P-Value & 0.397 & 0.428 & 0.094 & 0.499 \\
\hline
\end{tabular}

The results of Mann-Whitney test showed no significant difference between the study groups at different times in terms of mean systolic blood pressure (Table 6).

Table 6

Mean and standard deviation of systolic blood pressure at different hours after cesarean in paracetamol and control groups

\begin{tabular}{|lllll|}
\hline Group & $\mathbf{1 5}$ minutes & $\mathbf{3 0}$ minutes & $\mathbf{4 5}$ minutes & $\mathbf{6 0}$ minutes \\
\hline Paracetamol & $107.67 \pm 20.36$ & $99.83 \pm 20.66$ & $103.17 \pm 14.38$ & $106.81 \pm 14.18$ \\
\hline Control & $107.17 \pm 19.70$ & $104.42 \pm 19.35$ & $107.48 \pm 15.36$ & $109.39 \pm 13.33$ \\
\hline P-Value & 0.786 & 0.273 & 0,053 & 0.228 \\
\hline
\end{tabular}

However, Mann-Whitney test showed a significant difference between groups in diastolic blood pressure at 15 and 45 minutes after cesarean (Table 7). 
Table 7

Mean and standard deviation of diastolic blood pressure at different hours after cesarean in paracetamol and control groups

\begin{tabular}{|lllll|}
\hline Group & 15 minutes & 30 minutes & 45 minutes & 60 minutes \\
\hline Paracetamol & $60.67 \pm 12.88$ & $55.67 \pm 14.07$ & $54.50 \pm 12.08$ & $57.93 \pm 13.09$ \\
Control & $63.42 \pm 12.73$ & $57.81 \pm 14.74$ & $57.63 \pm 13.31$ & $58.20 \pm 13.17$ \\
\hline P-Value & 0.046 & 0.255 & 0.042 & 0.885 \\
\hline
\end{tabular}

There were no unwanted side effects in the participants in the two groups.

\section{Discussion}

This study was carried out on 240 pregnant women undergoing cesarean section. The results showed that since postoperative pain was a very common complication, especially in cesarean section, preoperative administration of intravenous paracetamol could significantly induce anesthetic effect, reduce the required pethidine after surgery and prevent its harmful effects such as respiratory dysfunctions, maternal nausea and neonatal sleepiness. This result was obtained through measurement of pain in patients using VAS and number of post-cesarean pethidine administrations.

Most studies have emphasized the anesthetic effects of paracetamol. Kiliçaslan et al. compared the patients' post-cesarean pain score in two groups $(n=25)$, one receiving intravenous paracetamol plus tramadol and one receiving tramadol alone. They concluded that pain score was lower in paracetamol group (17). Inal conducted a study on 50 patients under cesarean surgery and compared the analgesic effect of paracetamol and meperidine. They found that paracetamol led to reduction of pain score in the patients (18). In another study, Ali and Khan compared the analgesic impact of tramadol plus paracetamol and tramadol alone on 60 patients undergoing laparoscopic surgery and they obtained the same results as presented above (19). Cattabriga et al. investigated the analgesic effect of paracetamol on postoperative pain in patients undergoing cardiac surgery and reported that intravenous paracetamol could induce appropriate analgesic effect in the patients (20). In all studies cited above, the frequency of administration and total dose of narcotic analgesic were reduced when paracetamol was administered.

However, some studies have shown no significant difference between the analgesic effect of paracetamol and narcotic analgesics, such as the study of Van Aken et al. that compared the analgesic effects of paracetamol and morphine in dental surgery (21) and that of Rawal et al. which compared the analgesic effect of oral tramadol and intravenous paracetamol in outpatient surgeries (22).

Vuilleumier et al. conducted a study in Switzerland in 1998 and compared the postoperative analgesic effect of paracetamol and morphine. They found that paracetamol could be used as a substitute to morphine to induce postoperative analgesia in moderate pain. They reported that morphine had a better short-term analgesic effect, but finally paracetamol had a longer analgesic effect (23). Nikoda et al. carried out a study in Russia in 2002 and examined the postoperative analgesic effects of Paracetamol on 30 
patients. They concluded that paracetamol reduce the severity of postoperative pain (24). In another study, Emir et al. compared the analgesic effect of tramadol plus paracetamol and tramadol alone on the spinal surgery and reported a higher efficacy of paracetamol (25). Mofidi et al. also conducted a study on 80 patients with renal pain and found that intravenous paracetamol to be a safe and effective drug with no remawrkable side effects in relieving pain in renal patients. Further, they reported paracetamol had a higher efficacy and fewer complications than tramadol in relieving the patients' renal pain (26).

In our study, the side effects such as nausea and chills were reported in both groups. Previous studies have mostly reported significantly fewer side effects in paracetamol group, due to reduced total dose of narcotic drug $(27,28)$.

Studies have used various scales for pain evaluation (27-29). With respect to pain measurement scale, we used VAS, and it is different from most other studies (1). However, some studies like that of Olonisakin et al. (2012) in Nigeria, which evaluated the saving efficacy of intravenous paracetamol in using morphine for postoperative pain in women, had used the same scale (28). Yet, this difference did not affect the results.

Pain had a descending trend in both groups during the study period, which is in agreement with patient's gradual improvement and reduction of neural damages. Further, pain during administration was significantly lower in all four administrations in paracetamol group. Moreover, this difference in pain level was not observed in both groups 1 and 2 hours after administration, and patients in both groups experienced a similar pain. Hence, it can be concluded that intravenous paracetamol has had a longer efficacy, causing persistent pain relief and significant difference in pain level in both groups until next administration. Generally, pain level was different in both groups; pain reduction was greater in paracetamol group, this difference is statistically significant. This result is similar to some studies, such as Sinatra et al. study (2005) that investigated the effect and safety of single and repeated administration of $1 \mathrm{~g}$ intravenous paracetamol for pain management following large orthopedic surgery (30), study of Olonisakin et al. (2012) on the saving effect of intravenous paracetamol on using morphine for postoperative pain control in women (28) and study of Iqbal (2009) on the analgesic level and quality of postoperative intravenous administration of paracetamol and reduction of narcotic requirement (31).

However, some studies like that of Uysal et al. (2011) on comparative analysis of efficacy of intravenous paracetamol versus tramadol for postoperative analgesia in pediatric adenotonsillectomy (32), study of Kiliçaslan et al. (2010) on the effect of intravenous paracetamol on postoperative analgesia and tramadol on cesarean Sect. (17) and that of Lee et al. (2010) on the effect of paracetamol, ketorolac and paracetamol plus morphine on pain control after thyroidectomy showed no significant difference between the two groups in terms of pain reduction, the only advantage being quicker rehabilitation (33).

The present study found nausea and chills in both paracetamol and control groups although no significant difference was observed. Sanjar Mousavi and Khalili reported dizziness, nausea, headache, vomiting, sleepiness and immobility in both groups receiving paracetamol and opioid for postoperative pain relief, but no significant difference was observed between groups (34). 
The findings of the present study indicated no significant difference between the two groups in systolic blood pressure in different measurement stages, during and after cesarean, but diastolic blood pressure 15 minutes after start of cesarean section was significantly lower in paracetamol group than control group. Further, diastolic blood pressure 45 minutes after cesarean was significantly lower in paracetamol group than control group. Since blood pressure drop is not a common side effect of paracetamol administration, it can be concluded that paracetamol prevents increase of blood pressure increase by relieving pain in patients. Based on the results of Beyzaee et al., systolic blood pressure changes in both groups underwent significant changes over time, reducing three hours after surgery and then rising again, but no significant difference was found between paracetamol and control groups with respect to systolic blood pressure. Similarly, their results showed significant changes in diastolic blood pressure over time in both groups, but the difference between two groups was not statistically significant (35).

Unrelieved postoperative pain can lead to complications such as nausea, vomiting, hypertension, increased heart rate, myocardial ischemia, pulmonary atelectasis, hypoxia, dyspnea, coughing, decreased respiratory volume, urinary retention, increased coagulation and thrombosis, immunosuppression, anxiety, insomnia, central sensitization and chronic pain. Thus, specialists have always tried to find out appropriate and lowrisk techniques to eliminate or reduce pain in patients.

For a long time, opioids drugs were the main choice for postoperative pain relief, but they are used less due to adverse effects such as respiratory depression, nausea, vomiting, slow gastrointestinal function and reduced consciousness, which delays rehabilitation and movement. Nowadays, various methods have been suggested for decreasing opioids use, one of which is use of non-narcotic drugs along with or as a substitute to narcotic drugs. Recently, paracetamol, which is an analgesic and antipyretic medication, is administered intravenously before, during and after surgery. Use of this drug before surgical has shown favorable effects in different studies (36), which is in line with the results of the current study. Numerous studies have been done on the efficacy of this pain relief method, which have mainly indicated adequate analgesia, lower sleepiness, less side effects, accelerated rehabilitation and reduced use of opiates after surgery.

Since the effects of a drug have been studied in this study and the drugs have specific pharmacogenetic effects, so the results of this study can be extended to other races and communities.

\section{Conclusion}

This study showed that intravenous administration of paracetamol induced great analgesic effects on postcesarean pain and reduced the frequency and total dose of pethidine despite statistically insignificant difference. If future studies confirm this result, intravenous paracetamol can be used extensively as an adjuvant medication or even a substitute to opioids in cesarean.

\section{Abbreviations}

$\mathrm{BMI}$ 
Body Mass Index

VAS

Visual Analogue Scale

NSAIDs

Non-Steroidal Anti-Inflammatory Drugs

IRCT

Iranian Registry of Clinical Trial

NPO

Nil Per Os

MAP

Mean Arterial Pressure

\section{Declarations}

\section{Ethic approval and consent of participate}

The proposal of present study approved by the Research Council of Rafsanjan University of Medical Sciences with No. 841 on 2016-11-08 and by the ethics committee of Rafsanjan University of Medical Sciences, with code IR.RUMS.REC.1395.115 on 2016-11-08 and approved by the Iranian Registry of Clinical Trial (IRCT) with code IRCT20150519022320N17 on 2019-01-18 (retrospectively registered). https://www.irct.ir

\section{Consent for publication}

Not applicable

\section{Availability of data and materials}

All data generated or analyzed during this study are included in this published article.

\section{Competing interests}

The authors declare that they have no competing interests.

\section{Funding}

Rafsanjan University of Medical Sciences funded this article (proposal No. 841). Funding was used to procure equipment, purchase medicines, reproduce questionnaires, and data analysis.

\section{Authors' contribution}

SH PAKZAD MOGHADAM: Study design in the field of anesthesia and drug administration.

M POURPARIZI: Selecting patients, describing research steps to patients, and assisting in writing articles 
R GOUJANI: Statistic analysis

T MIRZAEI KHALILABADI: Questionnaire completion

A RAVARI: Questionnaire design

S ASKARI: Questionnaire completion

S MIRZAEI KHALILABADI: Design study in midwifery part, performing surgeries and writing articles.

\section{All authors have read and approved the final version of manuscript}

Acknowledgment: Anesthesiology and maternity nursing staff helped us in this study, and we appreciate them for their cooperation. We also thank Doctor Foad Iranmanesh; assistant professor of Rafsanjan University of Medical Sciences for his help in the writing, editing and submitting the article.

\section{References}

1. Nielson WR. The concept of pain. The Clinical journal of pain. 2001 Dec;17(4 Suppl):S5-7. PubMed PMID: 11783832. Epub 2002/01/11. eng.

2. Lavand'homme P. [Chronic pain after surgery: State of the art]. Presse medicale (Paris, France : 1983). 2015 May;44(5):486-91. PubMed PMID: 25683102. Epub 2015/02/17. Douleurs chroniques apres chirurgie : etat des lieux. fre.

3. Jakobi P, Weiner Z, Solt I, Alpert I, Itskovitz-Eldor J, Zimmer EZ. Oral analgesia in the treatment of postcesarean pain. European journal of obstetrics, gynecology, and reproductive biology. 2000 Nov;93(1):61-4. PubMed PMID: 1100050 Epub 2000/09/23. eng.

4. Cuunningham F, Leveno K, Bloom S, Dashe J, Hoffman B, Casey B, et al. Williams Obstretrics. 25th ed: McGrawHill; 2018.

5. Vricella LK, Louis JM, Mercer BM, Bolden N. Anesthesia complications during scheduled cesarean delivery for morbidly obese women. American journal of obstetrics and gynecology. 2010 Sep;203(3):276 e1-5. PubMed PMID: 20673866. Epub 2010/08/03. eng.

6. Cheek TG, Baird E. Anesthesia for nonobstetric surgery: maternal and fetal considerations. Clinical obstetrics and gynecology. 2009 Dec;52(4):535-45. PubMed PMID: 20393407. Epub 2010/04/16. eng.

7. Bamigboye AA, Hofmeyr GJ. Non-closure of peritoneal surfaces at caesarean section-a systematic review. South African medical journal = Suid-Afrikaanse tydskrif vir geneeskunde. 2005 Feb;95(2):1236. PubMed PMID: 15751208. Epub 2005/03/09. eng.

8. Munishankar B, Fettes P, Moore C, McLeod GA. A double-blind randomised controlled trial of paracetamol, diclofenac or the combination for pain relief after caesarean section. International journal of obstetric anesthesia. 2008 Jan;17(1):9-14. PubMed PMID: 17981455. Epub 2007/11/06. eng.

9. Miller R, Eriksson L, Fleisher L, Wiener-Kronish J, Cohen N, Young W. Miller's Anesthesia. 8th ed: Saunders; 2014. 
10. Benyamin R, Trescot AM, Datta S, Buenaventura R, Adlaka R, Sehgal N, et al. Opioid complications and side effects. Pain physician. 2008 Mar;11(2 Suppl):S105-20. PubMed PMID: 18443635. Epub 2008/06/17. eng.

11. McNicol ED, Strassels S, Goudas L, Lau J, Carr DB. WITHDRAWN: NSAIDS or paracetamol, alone or combined with opioids, for cancer pain. The Cochrane database of systematic reviews. 2015 Jul 31(7):CD005180. PubMed PMID: 26230486. Epub 2015/08/01. eng.

12. Sweetman S. Martindale: The complete drug reference. 37th ed: Pharmaceutical Press; 2011.

13. Shams Vahdati S, Morteza Baghi HR, Ghobadi J, Rajaei Ghafouri R, Habibollahi P. Comparison of paracetamol (apotel(R)) and morphine in reducing post pure head trauma headache. Anesthesiology and pain medicine. 2014 Aug;4(3):e14903. PubMed PMID: 25237630. Pubmed Central PMCID: PMC4164985. Epub 2014/09/23. eng.

14. Grahame-Smith D, Aronson J. Oxford Textbook of Clinical Pharmacology and Drug Therapy. 3rd ed: Oxford; 2002.

15. Jabalameli M, Safavi M, Honarmand A, Saryazdi H, Moradi D, Kashefi P. The comparison of intraincisional injection tramadol, pethidine and bupivacaine on postcesarean section pain relief under spinal anesthesia. Advanced biomedical research. 2012;1:53. PubMed PMID: 23326784. Pubmed Central PMCID: PMC3544092. Epub 2013/01/18. eng.

16. Sousa Ld, Pitangui ACR, Gomes FA, Nakano AMS, Ferreira CHJ. Mensuração e características de dor após cesárea e sua relação com limitação de atividades. Acta Paulista de Enfermagem. 2009;22:741-7.

17. Kilicaslan A, Tuncer S, Yuceaktas A, Uyar M, Reisli R. [The effects of intravenous paracetamol on postoperative analgesia and tramadol consumption in cesarean operations]. Agri : Agri (Algoloji) Dernegi'nin Yayin organidir = The journal of the Turkish Society of Algology. 2010 Jan;22(1):7-12. PubMed PMID: 20209409. Epub 2010/03/09. Sezaryen cerrahisinde intravenoz parasetamolun postoperatif analjezi ve tramadol tuketimine etkisi. tur.

18. Inal MT. Treatment of fever and pain with paracetamol infusion after caesarean section. The Internet Journal of Pain, Symptom Control and Palliative Care. 2008;6:1-4.

19. Ali M, Khan FA. Comparison of analgesic effect of tramadol alone and a combination of tramadol and paracetamol in day-care laparoscopic surgery. (1365-2346 (Electronic)). eng.

20. Cattabriga I, Pacini D Fau - Lamazza G, Lamazza G Fau - Talarico F, Talarico F Fau - Di Bartolomeo R, Di Bartolomeo R Fau - Grillone G, Grillone G Fau - Bacchi-Reggiani L, et al. Intravenous paracetamol as adjunctive treatment for postoperative pain after cardiac surgery: a double blind randomized controlled trial. (1010-7940 (Print)). eng.

21. Van Aken H, Thys L Fau - Veekman L, Veekman L Fau - Buerkle H, Buerkle H. Assessing analgesia in single and repeated administrations of propacetamol for postoperative pain: comparison with morphine after dental surgery. (0003-2999 (Print)). eng.

22. Rawal N, Allvin R Fau - Amilon A, Amilon A Fau - Ohlsson T, Ohlsson T Fau - Hallen J, Hallen J. Postoperative analgesia at home after ambulatory hand surgery: a controlled comparison of tramadol, metamizol, and paracetamol. (0003-2999 (Print)). eng. 
23. Vuilleumier PA, Buclin T Fau - Biollaz J, Biollaz J. [Comparison of propacetamol and morphine in postoperative analgesia]. (0036-7672 (Print)). fre.

24. Nikoda Vv Fau - Maiachkin RB, Maiachkin RB. [Study of analgesic efficacy of propacetamol in the postoperative period using a double blind placebo controlled method]. (0201-7563 (Print)). rus.

25. Emir E, Serin S, Erbay RH, Sungurtekin H, Tomatir E. Tramadol versus low dose tramadol-paracetamol for patient controlled analgesia during spinal vertebral surgery. The Kaohsiung journal of medical sciences. 2010 Jun;26(6):308-15. PubMed PMID: 20538235. Epub 2010/06/12. eng.

26. Mofidi M, Shaker H, Ghafouri H. Comparison of Analgesia effect Between Intravenous Propacetamol and Tramadol. J-Mazand-Univ-Med-Sci. 2007;17(61):81-7.

27. Alhashemi JA, Daghistani MF. Effects of intraoperative i.v. acetaminophen vs i.m. meperidine on posttonsillectomy pain in children. British journal of anaesthesia. 2006 Jun;96(6):790-5. PubMed PMID: 16613928. Epub 2006/04/15. eng.

28. Olonisakin RP, Amanor-Boadu SD, Akinyemi AO. Morphine-sparing effect of intravenous paracetamol for post operative pain management following gynaecological surgery. African journal of medicine and medical sciences. 2012 Dec;41(4):429-36. PubMed PMID: 23672109. Epub 2013/05/16. eng.

29. Memis D, Inal MT, Kavalci G, Sezer A, Sut N. Intravenous paracetamol reduced the use of opioids, extubation time, and opioid-related adverse effects after major surgery in intensive care unit. Journal of critical care. 2010 Sep;25(3):458-62. PubMed PMID: 20189753. Epub 2010/03/02. eng.

30. Sinatra RS, Jahr JS, Reynolds LW, Viscusi ER, Groudine SB, Payen-Champenois C. Efficacy and safety of single and repeated administration of $1 \mathrm{gram}$ intravenous acetaminophen injection (paracetamol) for pain management after major orthopedic surgery. Anesthesiology. 2005 Apr;102(4):822-31. PubMed PMID: 15791113. Epub 2005/03/26. eng.

31. Iqbal K. Managing postoperative pain. The ORION Medical Journal 2009;32(1):623-8.

32. Uysal HY, Takmaz SA, Yaman F, Baltaci B, Basar H. The efficacy of intravenous paracetamol versus tramadol for postoperative analgesia after adenotonsillectomy in children. Journal of clinical anesthesia. 2011 Feb;23(1):53-7. PubMed PMID: 21296248. Epub 2011/02/08. eng.

33. Lee SY, Lee WH, Lee EH, Han KC, Ko YK. The effects of paracetamol, ketorolac, and paracetamol plus morphine on pain control after thyroidectomy. The Korean journal of pain. 2010 Jun;23(2):124-30. PubMed PMID: 20556214. Pubmed Central PMCID: PMC2886239. Epub 2010/06/18. eng.

34. Sanjar Mousavi N, Khalili R. Efficacy of intravenous Acetaminophen (Apotel) in control of pain after abdominoplasty. Medical Sciences Journal of Mashhad Islamic Azad University. 2014 05/22;4(1):1-17. fa.

35. Beyzaei H, Aliyan M, Najafı P, Zohoriyan Z. Evaluation the effect of intravenous parastamol at the end of cesarian section procedure on postoperative pain. Mashhad Azad Islami University Medical Sciences Journal. 2013;3(1):1-16.

36. Ong CK, Lirk P, Seymour RA, Jenkins BJ. The efficacy of preemptive analgesia for acute postoperative pain management: a meta-analysis. Anesthesia and analgesia. 2005 Mar;100(3):757-73, table of contents. PubMed PMID: 15728066. Epub 2005/02/25. eng. 
Figures

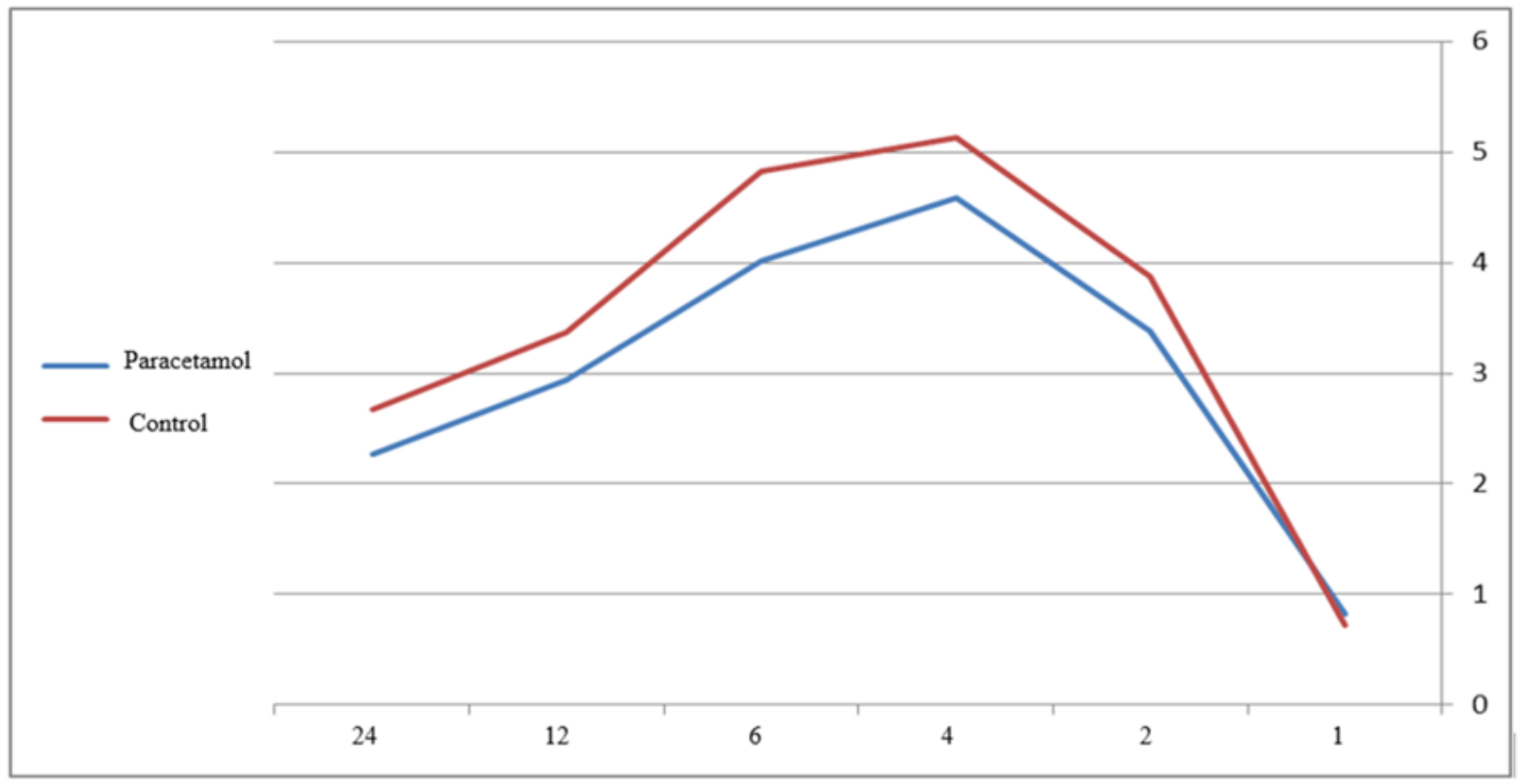

Figure 1

Mean of pain scores over time in paracetamol and control groups

\section{Supplementary Files}

This is a list of supplementary files associated with this preprint. Click to download.

- CONSORTFlowdiagram.docx

- CONSORT2010Checklist.doc 